\title{
SeMatching: Using Semantics to Perform Pair Matching in Mentoring Processes
}

\author{
Ricardo Colomo-Palacios, Juan Miguel Gómez-Berbís, \\ Ángel García-Crespo, and Myriam Mencke \\ Computer Science Department, Universidad Carlos III de Madrid \\ Av. Universidad 30, Leganés, 28911, Madrid, Spain \\ \{ricardo-colomo, juanmiguel.gomez, angel.garcia, \\ myriam.mencke\} @uc 3 m.es
}

\begin{abstract}
The importance of the human factor in 21st century organizations means that the competent development of professionals has become a key aspect. In this environment, mentoring has emerged as a common and efficient practice for the development of knowledge workers. Following the surge of concepts such as eMentoring, advancements of the Internet and its evolution towards a Semantic Web, such developments present novel opportunities for the improvement of the different characteristics of mentoring. Basing itself on such advancements, this paper presents SeMatching, a semantics-based platform which utilizes different personal and professional information to carry out pair matching of mentors and mentees.
\end{abstract}

Keywords: Semantic Web, Social Software, Mentoring, e-Mentoring, Pair Matching.

\section{Introduction}

The dramatic spread of the Internet throughout all levels of society has substantially transformed forms of communication, entertainment and acquisition of knowledge. A constantly increasing number of people encounter responses to their questions on the Internet on a daily basis, and have adapted it as a new form of communication. These novel forms of social behavior have had the result that user preferences and behavior can be easily obtained, which combined with a user's professional data, represent an opportunity for knowledge management initiatives. In order to fully exploit such initiatives, it is necessary to rely on technological tools which enable the organization and exploitation of data for a determined objective.

Regarding the concept of mentoring, since the end of the 1970s, mentoring has become a business practice for staff development which has attained general application. This practice has also been influenced by the boom of the Internet, and the immediate consequence of this has been the appearance of e-Mentoring. The focus of the current paper finds itself at the union of mentoring with the new capabilities of the Internet, and has been named SeMatching. SeMatching has been conceived as a tool based on the Semantic Web (SW) to facilitate pair matching in mentoring. The tool can be used in both traditional mentoring environments, as well as for e-Mentoring. 


\section{2 eMentoring: A New Social Tool, an Ancient Way of Career Development}

The concept of mentoring dates back to the earliest stages of human civilization [1]. The origins of the mentoring term can be traced back to the history of Ancient Greece. In Homer's masterpiece, "The Odyssey", Ulysses, king of Ithaca, delegates his house and the education of his son, Telemachus to Mentor, when he leaves for the Troy War (traditionally dated 1193 BC-1183 BC). However, different authors [2] claim that, despite the term having its origin in Ancient Greece, the concept stems from methods and techniques of three Chinese kings, Yao, Shun and Yu between approximately 2333 and 2177 BC. Therefore, despite the importance of the classical Greek etymology, the Chinese origin is earlier than the Greek one.

Apart from its origin, current literature stemming from a number of disciplines (Management, Social Psychology, Sociology...) has provided a significant number of studies about mentoring from the late seventies to the 20th century. As a consequence of the interest raised by the topic and its broad application to business environments, multiple definitions of the term have been coined. Hence [3] have undertaken a reconceptualization of the term from an in-depth study of existing literature definitions. Mentoring has thus been defined as an improvement process concerning a number of aspects related to a professional career, but also with the global improvement of the individual, which requires a senior advisor and a junior protégé. The relationship established implies benefits for both sides involved. The protégé obviously achieves a remarkable improvement in his professional career, promotion-wise [4], [5], a higher income [4], [6] and more satisfaction and social acceptance in the working environment [7]. On the other hand, mentors benefit from high-speed promotions, reputation and personal satisfaction [8], [9], [5]. Finally, organizations consequently gain a higher motivation from employees, more working stability and the improvement of leadership and development skills in its core [8], [10], [11], being able to rely on employees with more adaptation skills, ready to face a decision making process with more guarantees [12], develop social capital in broader social networks [13] and finally, support knowledge transfer across projects [14].

As discussed in [15], there are three main factors, codenamed as "demographic" that might influence the productivity of the mentoring relationship: firstly, the duration, and secondly the type (formal or informal) and, lastly, the demographic composition of the relationship (in terms of gender and race, mostly, the latter quite variable and more relevant in inter-cultural societies such as in the USA). The first two variables are interconnected, it has been proved that informal mentoring relationships take more time and outperform formal relationships in terms of professional development [7]. Concerning demographic compositions, different features of the binomial structure also affect the final outcome of the process, both sides being of the same race and gender being the most productive relationships [15].

Due to the capabilities of technology of setting up new communication means and paradigms among people, the envisagement of electronic communication as a means for mentoring relationships was immediate. E-Mentoring refers to the process of using electronic means as the primary channel of communication between mentors and protégés [16]. The key distinction between electronic mentoring and traditional mentoring (t-Mentoring) is reflected in the face-to-face time between mentors and protégés. The communication means used by both sides is absolutely different in the 
two mentoring types. While traditional mentoring uses face-to-face relationships, eMentoring, which also harnesses face-to-face relationships, particularly at the beginning of the relationship, is principally based on email, chat, instant messaging and several other Internet applications. In [17], authors point out that e-Mentoring communication can take place synchronously (for example, electronic chat, instant messaging) or asynchronously (for example, email, message boards).

As previously outlined, e-Mentoring is a type of mentoring, based totally or partially on electronic communication. Due to the large amount of electronic communication instruments, a remarkable number of different names for the e-Mentoring concept have been provided. According to Perren [18], e-Mentoring can be seen to encompass a range of terms: computer-mediated mentoring, tele-Mentoring, e-mail mentoring, Internet mentoring, online mentoring and virtual mentoring.

Although Evans and Volery [19] suggested from their survey of experts that e-Mentoring is "second-best" and should only be seen as a supplement to face-to-face mentoring, there are many other studies in which e-Mentoring is considered as a valid vehicle to overcome some of the barriers posed by t-Mentoring. E-Mentoring provides flexibility and easy access, which is highly beneficial to those who may face barriers to being mentored, because of their gender, ethnicity, disability or geographical location [20]. Hamilton and Scandura [16] also analyze the advantages of e-Mentoring compared with t-Mentoring. These advantages are classified into three groups:

- Organizational structure

- $\quad$ Individual \& interpersonal factors

- $\quad$ Flexible / alternative work arrangements

Firstly, regarding the organizational structure, e-Mentoring eliminates geographical barriers characteristic of face-to-face interactions, smoothes status differences within the organization and increases the pool of available mentors. Secondly, concerning individual and interpersonal factors, the absence of face-to-face interactions decreases and minimizes gender or ethnical issues impact by increasing the effectiveness of mentors with a lack of social skills. Finally, regarding flexible or alternative work arrangements, the ability and actual capability of performing asynchronous communications implies the elimination of temporal barriers or caveats. In addition, communication is not geographically bound.

Other studies provide further arguments which support the work of Hamilton and Scandura [16]. Hence, following this trend, Warren and Headlam-Wells [21] observed that t-Mentoring, typically operating in large organizations, tends to cast the mentee as a passive recipient of structured formal provision of mentoring. In contrast, the use of the Web as a communication means provides improved access for the mentor and the mentee, and as stated by [16], creates a larger pool of potential mentors and mentees [22]. In addition, as with other e-learning programmes, a major advantage of an e-Mentoring system is its cost effectiveness [23], [24]. There are high start-up costs, but once established, the operational costs are relatively low. Costs related to travel or time away from the job and costs of updating learning resources can be reduced. Lastly, a record of the "discussion" usually exists for later reflection and learning [24]. To summarize, it is possible to state, as discussed by Clutterbuck and Cox [25], that e-Mentoring will be able to overcome many of the problems characteristic of t-Mentoring.

Nevertheless, not all e-Mentoring features are win-win for the mentor-mentee relationship. Eby, McManus, Simon and Russell [26] conducted empirical work in this 
area that further examined the dark side of mentoring, and developed a useful taxonomy of negative experiences from the mentee perspective using qualitative data. These authors make important distinctions between what is considered negative and how that might be different from the perspective of the mentee and the mentor. A later study conducted by Ensher, Heun and Blanchard [27] uses the findings of [26] to identify five major challenges in e-Mentoring: (1) likelihood of miscommunication, (2) slower development of the relationship online than in face-to-face mentoring, (3) the relationship requires competency in written communication and technical skills, (4) computer malfunctions, and (5) issues of privacy and confidentiality.

Pair matching criteria is one of the most important issues in both e-Mentoring and tMentoring. This concept is based on the assignment of a mentor to a mentee depending of a number of parameters defined with the purpose of harnessing the mentorship. Such parameters might include values, gender coincidences, related professional experience, and so on. Despite it being a key issue of concern for mentoring, crucial according to [24], there is little research concerning the matching of pairs [23]. Cohen and Light [28] argue that matching solely on the basis of mentees needs and mentors' skills may not be enough to ensure successful matches, and suggest that personality factors may also be significant. Indeed, successful mentoring relationships are often reported as those where mentees felt they shared their mentors' personal values [23].

With the exception of a small number of mentoring programmes which use a formal matching system, most tend to use a 'hand-sift' method, whereby mentees are matched with a mentor who suits their needs [29]. However, if a number of people of remarkable size is faced, this type of selection can unfortunately not be applied. Therefore, [29] suggest a set of eleven criteria that allow the automation of the process, together with application criteria:

Table 1. Matching criteria proposed by [29] for automatic pair matching

\begin{tabular}{|c|c|}
\hline Criterion & Explanation \\
\hline Age & Mentee matched with older mentor. \\
\hline $\begin{array}{l}\text { Number of years work } \\
\text { experience }\end{array}$ & $\begin{array}{l}\text { Mentee matched with mentor with more work } \\
\text { experience. }\end{array}$ \\
\hline Level of qualification & $\begin{array}{l}\text { Mentee matched with mentor with higher } \\
\text { qualification level. }\end{array}$ \\
\hline Marital status & $\begin{array}{l}\text { Mentee matched with mentor with same marital } \\
\text { status. }\end{array}$ \\
\hline Children & $\begin{array}{l}\text { Mentee matched with mentor in a similar situation to } \\
\text { themselves (having/had children). }\end{array}$ \\
\hline Dependent care & Mentee matched with mentor in a similar situation. \\
\hline Life/career histo & $\begin{array}{l}\text { Identify similarities in life/career experiences, e.g. } \\
\text { having experienced barriers to progression. }\end{array}$ \\
\hline Personal skills & $\begin{array}{l}\text { Mentee matched with mentor who could help them } \\
\text { develop the personal skills they need to improve. }\end{array}$ \\
\hline Professional skills & $\begin{array}{l}\text { Mentee matched with mentor who could help them } \\
\text { develop the professional skills they need to improve. }\end{array}$ \\
\hline Vocational sector & $\begin{array}{l}\text { Mentee matched with mentor who worked/had } \\
\text { worked in a similar occupational area. }\end{array}$ \\
\hline Personal values & $\begin{array}{l}\text { Mentee matched with mentor who shared similar } \\
\text { core values. }\end{array}$ \\
\hline
\end{tabular}




\section{SeMatching: New Tool, Ancient Needs}

In today's organizations, the capabilities of Information Communication Technology (ICT) have transformed not only forms of communication, but also the forms of personal development in professional environments. In particular, the arrival of the SW represents a revolution in the forms of accessing and storage of information. The SW term was coined by [30] to describe the evolution from a document-based web towards a new paradigm that includes data and information for computers to manipulate. The SW provides a complementary vision as a knowledge management environment [31] that, in many cases has expanded and replaced previous knowledge management archetypes [32]. In this new scenario, SW technology has been identified as a factor which can be exploited in the environment of mentoring. According to [33], "Mentors can be semantically selected by matching profiles".

The application of semantics in relation to the management of human capital in organizations is not a new concept. One of the research areas which holds the longest tradition relates to the analysis of competencies. According to McClelland [34], competence concerns the relation between humans and work tasks: rather than knowledge and skills themselves, competence involves the knowledge and skills required to perform a specific job or task in an efficient way. More recently, HR-XML defined competency as a specific, identifiable, definable, and measurable knowledge, skill, ability and/or other deployment-related characteristic (for example, attitude, behavior, physical ability) which a human resource may possess and which is necessary for, or fundamental to, the performance of an activity within a specific business context. Various initiatives which propose the use of this new technology have been seen as a result of the popularity of the competency concept and the growth of the SW. The technology has been applied for the training of work teams [35], filling competency gaps in organizations [36], analyzing competency gaps [37], knowledge management for software projects [38], knowledge sharing and reuse [39], assist the learning process [40] or assist work assignment [41] to cite some of the most recent initiatives. Zülch and Becker [42] expressed the need for a fixed terminology of competencerelated concepts, and Schmidt and Kunzmann [43] pointed out that Ontology-based approaches are the solution for the crucial trade-off in competency modeling needs. Taking those two conclusions into account, all of the works mentioned use ontologies as a tool. Thus ontologies are the appropriate formalisms to represent competency concepts. Similarly, in the current work, ontologies can be used to represent pair matching concepts. The theory which supports the use of ontologies is a formal theory within which not only definitions but also a supporting framework of axioms is included [44].

However, neither the competency ontologies used, nor some of the standardization efforts on modeling competencies can cover all of the characteristics which pair matching spans. An adaptation of the available competency ontologies is required. The LUISA Project (http://luisa.atosorigin.es) addresses the development of a reference semantic architecture for the major challenges in the search, interchange and delivery of learning materials. A deliverable of this project is the Generic Competence Ontology (GCO).Using this specification as a base which is adapted for mentoring pair matching issues, many of the criterions can be directly included just by using concepts from the ontology (person, competency, attitude, skill, job position...), while 
others must be updated (Vocational sector, Personal values... ). As a result of this, a modified version of GCO adapted to mentoring scenario is used here. The figure below demonstrates the architecture of Sematching:

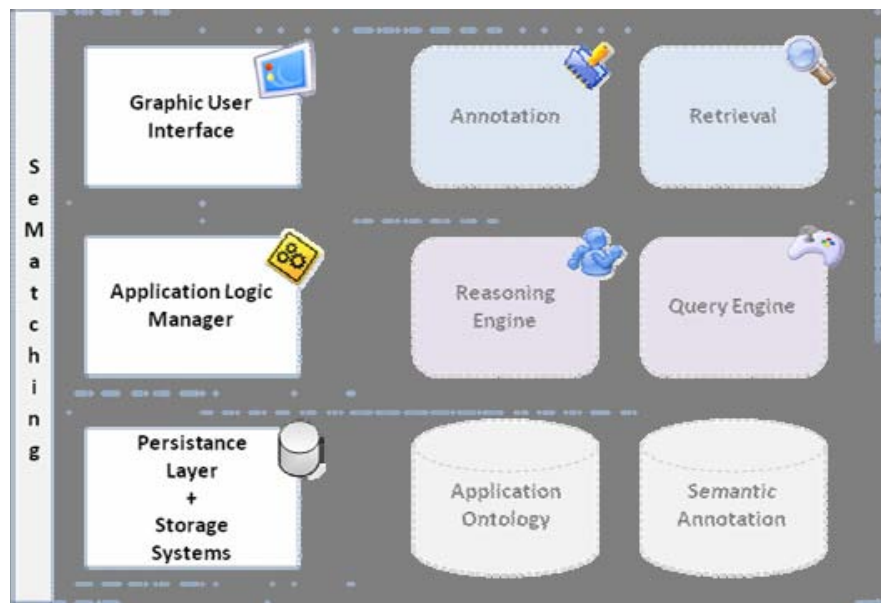

Fig. 1. Sematching Architecture

The current section details the different components of the architecture without specifically focusing on the software layer where they belong. This is not necessary, since the three functionalities are well defined and have a commonly shared and used pattern:

- Annotation GUI: This component interacts with the user by providing a set of graphical elements to annotate the resources by means of semantic annotations based on the ontology used.

- Retrieval GUI: It offers a semantic annotation retrieval functionality for the user, based on both the Reasoning Engine and the Query Engine. In the former, retrieval is envisaged as location of a subset of concepts by means of Description Logics subsumption. In the latter, the retrieval is provided by SPARQL definitions to find, manage and query RDF triples following a particular criteria.

- Reasoning Engine: This component derives facts from a knowledge base, reasoning about the information with the ultimate purpose of formulating new conclusions. In the SeMatching framework, it consists of an OWL Description Logics based reasoner, such as the Renamed ABox and Concept Expression Reasoner (RACER). It uses subsumption to find sets and subsets of annotations based on logical constraints.

- Query Engine: The Query Engine component uses the SPARQL RDF query language to make queries into the storage systems of the back end layer. The semantics of the query are defined not by a precise rendering of a formal syntax, but by an interpretation of the most suitable results of the query. This is because SeMatching stores mostly RDF triples or OWL DL ontologies, which also present an RDF syntax. 
- Semantic Annotation and Application Ontology Repositories: These two components are semantic data store systems that enable ontology persistence, querying performed by the Business Logic layer components and offer a higher abstraction layer to enable fast storage and retrieval of large amounts of OWL DL ontologies, together with their RDF syntax. This ensures that the architecture has a small footprint effect and a lightweight approach. An example of such systems could be the OpenRDF Sesame RDF Storage system, or the Yet Another RDF Storage System (YARS), which deal with data and legacy integration.

The SeMatching architecture is a self-contained, loosely coupled open architecture which allows using a wide range of software technologies for its implementation. The added value of SeMatching will be, taking into account its SW orientation, the inclusion of really "soft" aspects like values in the ontology model. Many of the concepts that are related to pair matching (soft and hard skills, career history, qualification...) are used in other semantic efforts e.g. [38], [41], however the inclusion of values (which according to some authors are also present in competences, but as a part of it) in this scenario is new. In the other hand, in comparision with traditional pair matching process, the use of ontologies can provide a common vocabulary and the undeniable matching that is associated with this approach.

Many organizations are facing vitualization, outsourcing and offshoring. In this new scenario, mentoring, and, in particular, eMentoring can be a way to preserve organizational culture in complex work layouts. Thus, SeMatching can be seen as enabling technology for these organizations in which both knowledge and workers are scattered. Those organizations, like any others, need to preserve their culture by performing a good mentoring process based on new pair matching processes.

\section{Conclusions and Future Work}

Taking into account the progressive virtualization of organizations, SeMatching represents a latent opportunity for organizations interested in the development of their intellectual capital. SeMatching represents an innovative and technologically advanced initiative, which takes advantage of the capacities that the SW provides.

The current work proposes two types of initiatives which should be explored in future research. In the first place, the integration of the functionalities provided by Web 2.0 in the development of the profiles of the mentors and mentees. Populating the ontologies based on available social information represents a research opportunity which has been previously developed by the authors, and this data is considered here as an invaluable source for the creation of user preference profiles. Furthermore, these preference profiles may be very useful data sets for the addition of personal preferences in the pair matching process. In the second place, it is aimed to test the platform developed empirically by evaluating the capabilities of SeMatching from a qualitative viewpoint. The researchers envisage testing the platform using a set of tests carried out by experts who validate the platform from a qualitative perspective. From a quantitative perspective, authors are working in the prototype of SeMatching in order to perform a pilot study in an Spanish university. 


\section{References}

1. Kammeyer-Mueller, J.D., Judge, T.A.: A quantitative review of mentoring research: Test of a model. Journal of Vocational Behavior 72, 269-283 (2008)

2. Huang, C.A., Lynch, J.: Mentoring: The Tao of Giving and Receiving Wisdom. Harper Collins, San Francisco (1995)

3. Friday, E., Friday, S.S., Green, A.L.: A reconceptualization of mentoring and sponsoring. Management Decision 42(5), 628-644 (2004)

4. Dreher, G.F., Ash, R.A.: A comparative study of mentoring among men and women in managerial, professional, and technological positions. Journal of Applied Psychology 75, 539-546 (1990)

5. Scandura, T., Tejeda, M., Werther, W., Lankau, M.: Perspectives on Mentoring. Leadership \& Organization Development Journal 17(3), 50-58 (1996)

6. Whitely, W.T., Dougherty, T.W., Dreher, G.F.: Relationship of career mentoring and socioeconomic origin to managers' and professionals' early career progress. Academy of Management Journal 34, 331-351 (1991)

7. Chao, G.T., Walz, P.M., Gardner, P.D.: Formal and informal mentorships: A comparison on mentoring functions and contrast with nonmentored counterparts. Personnel Psychology 45, 619-636 (1992)

8. Hunt, D.M., Michael, C.: Mentorship: a career training and development tool. Academy of Management Review 8(3), 475-485 (1983)

9. Zey, M.G.: The Mentor Connection. Irwin, Homewood (1984)

10. Viator, R.E., Scandura, T.A.: A study of mentor-protégé relationships in large public accounting firms. Accounting Horizon 5(3), 20-30 (1991)

11. Levesque, L.L., O'Neill, R.M., Nelson, T., Dumas, C.: Sex differences in the perceived importance of mentoring functions. Career Development International 10(6), 429-443 (2005)

12. Ragins, B., Scandura, T.: Burden or blessing? Expected costs and benefits of being a mentor. Journal of Organizational Behavior 20(4), 493-510 (1999)

13. Hezlett, S.A., Gibson, S.K.: Linking Mentoring and Social Capital: Implications for Career and Organization Development. Advances in Developing Human Resources 9(3), 384-411 (2007)

14. Landaeta, R.E., Kotnour, T.G.: Formal mentoring: a human resource management practice that supports knowledge transfer across projects. International Journal of Learning and Intellectual Capital 5(3/4), 455-475 (2008)

15. Nielson, T.R., Eisenbach, R.J.: Not All Relationships are Created Equal: Critical Factors of High-Quality Mentoring Relationships. The International Journal of Mentoring and Coaching 1(1) (2003)

16. Hamilton, B.A., Scandura, T.A.: E-Mentoring: implications for organizational learning and development in a wired world. Organizational Dynamics 31, 388-402 (2003)

17. Smith-Jentsch, K.A., Scielzo, S.A., Yarbrough, C.S., Rosopa, P.J.: A comparison of faceto-face and electronic peer-mentoring: Interactions with mentor gender. Journal of Vocational Behavior 72, 193-206 (2008)

18. Perren, L.: The role of e-Mentoring in entrepreneurial education \& support: a meta-review of academic literature. Education \& Training 45(8/9), 517-525 (2003)

19. Evans, D., Volery, T.: Online business development services for entrepreneurs: an exploratory study. Entrepreneurship and Regional Development 13(4), 333-350 (2001)

20. Bierema, L., Hill, J.: Virtual mentoring and HRD. Advances in Developing Human Resources 7(4), 556-568 (2005) 
21. Warren, L., Headlam-Wells, J.: Mentoring women entrepreneurs: A better approach. Organisations and People 9(2), 11-17 (2002)

22. Packard, B.W.: Web-based mentoring: Challenges traditional models to increase women's access. Mentoring and Tutoring 11(1), 53-65 (2003)

23. Headlam-Wells, J., Gosland, J., Craig, L.: There's magic in the web: e-Mentoring for women's career development. Career Development International 10(6/7), 444-459 (2005)

24. Hunt, K.: E-Mentoring: solving the issue of mentoring across distances. Development and learning in organizations 19(5), 7-10 (2005)

25. Clutterbuck, D., Cox, T.: Mentoring by wire. Training Journal 35-39 (November 2005)

26. Eby, L.T., McManus, S.E., Simon, S.A., Russell, J.E.: The Protégés perspective regarding negative mentoring experiences: the development of a taxonomy. Journal of Vocational Behavior 57, 1-21 (2000)

27. Ensher, E.A., Heun, C., Blanchard, A.: Online mentoring and computer-mediated communication: New directions in research. Journal of Vocational Behavior 63(2), 264-288 (2003)

28. Cohen, K.J., Light, J.C.: Use of electronic communication to develop mentor-protégé relationships between adolescent and adult AAC users: pilot study. Augmentative and Alternative Communication 16, 227-238 (2000)

29. Headlam-Wells, J., Gosland, J., Craig, L.: Beyond the organisation: The design and management of E-Mentoring systems. International Journal of Information Management 26, 372-385 (2006)

30. Berners-Lee, T., Hendler, J., Lassila, O.: The Semantic Web. Scientific American 284(5), 35-40 (2001)

31. Warren, P.: Knowledge Management and the Semantic Web: From Scenario to Technology. IEEE Intelligent Systems 21(1), 53-59 (2006)

32. Davies, J., Lytras, M., Sheth, A.P.: Semantic-Web-Based Knowledge Management. IEEE Internet Computing 11(5), 14-16 (2007)

33. Sicilia, M.A., Lytras, M.D.: The semantic learning organization. The learning organization 12(5), 402-410 (2005)

34. McClelland, D.C.: Testing for competence rather than for 'intelligence'. American Psychologist 28, 1-14 (1973)

35. Gómez-Berbís, J.M., Colomo-Palacios, R., García Crespo, A., Ruiz-Mezcua, B.: ProLink: A Semantics-based Social Network for Software Project. International Journal of Information Technology and Management 7(4), 392-404 (2008)

36. Colomo-Palacios, R., Ruano-Mayoral, M., Gómez-Berbís, J.M., García Crespo, A.: Semantic Competence Pull: A Semantics-Based Architecture for Filling Competency Gaps in Organizations. In: García, R. (ed.) Semantic Web for Business: Cases and Applications. IGI Global (2008)

37. De Coi, J.L., Herder, E., Koesling, A., Lofi, C., Olmedilla, D., Papapetrou, O., Sibershi, W.: A model for competence gap analysis. In: Proceedings of 3rd International Conference on Web Information Systems and Technologies (WEBIST), Barcelona, Spain (2007)

38. Colomo-Palacios, R., Gómez-Berbís, J.M., García-Crespo, A., Puebla Sánchez, I.: Social Global Repository: using semantics and social web in software projects. International Journal of Knowledge and Learning 4(5), 452-464 (2008)

39. Lanzenberger, M., Sampson, J., Rester, M., Naudet, Y., Latour, T.: Visual ontology alignment for knowledge sharing and reuse. Journal of Knowledge Management 12(6), 102-120 (2008) 
40. Naeve, A., Sicilia, M.A., Lytras, M.D.: Learning processes and processing learning: from organizational needs to learning designs. Journal of Knowledge Management 12(6), 5-14 (2008)

41. Macris, A., Papadimitriou, E., Vassilacopoulos, G.: An ontology-based competency model for workflow activity assignment policies. Journal of Knowledge Management 12(6), 72 88 (2008)

42. Zülch, G., Becker, M.: Computer-supported competence management: Evolution of industrial processes as life cycles of organizations. Computers in Industry 58(2), 143-150 (2007)

43. Schmidt, A., Kunzmann, C.: Sustainable Competency-Oriented Human Resource Development with Ontology-Based Competency Catalogs. In: Cunningham, M., Cunningham, P. (eds.) eChallenges (2007)

44. Smith, B.: Ontology. An Introduction. In: Floridi, L. (ed.) Blackwell Guide to the Philosophy of Computing and Information, pp. 155-166. Blackwell, Oxford (2003) 